\title{
Chapter 86 \\ BiOrganic Design: A New Method \\ for Architecture and the City
}

\author{
Alessandra Capanna
}

\section{Introduction}

Over the last 20 years, many architects have proclaimed a new design philosophy based on the emergent condition of complex-systems science, which opposes conventional analytical methodology, or reductionism, and non-linear processes including computer aided design.

There are those who claim that with the support of computers, entirely new forms of design have become possible and others who believe that computers have even modified the creative processes and design theory. In this sense, architects are involved in scientific investigations of artificial life, genetic algorithms and neural network programs.

Artificial Intelligence supporting the development of digital systems, both those produced for self-generated architectures as well as those for drawing topological transformations in Euclidean space is evolving faster than human intelligence and it has often been speculated that it is only a matter of time before our machines become smarter than us.

It is true that the use of digital systems for animation, on which programs such as ALIAS and MAYA are based, has had a liberating and cathartic effect on architects, enabling them to draw and control unusual shapes with high levels of complexity.

First published as: Alessandra Capanna, "BiOrganic Design. A New Method for Architecture and the City". Pp. 11-20 in Nexus VI: Architecture and Mathematics, Sylvie Duvernoy and Orietta Pedemonte, eds. Turin: Kim Williams Books, 2006.

A. Capanna $(\square)$

Dipartimento di Architettura e Progetto, Università di Roma "La Sapienza", Via Flaminia, 35900196 Rome, Italy

e-mail: alessandra.capanna@uniroma1.it 
The idea is not to automate design. It is not about being able to complete a design with a click of the mouse ... It is about higher quality, not more efficiency. We want it to be better, not faster. It is also not about having the computer create a large number of proposals from which to choose. It is not about using computers to create unusual forms. When used like that, a computer would be nothing more than an extension of the pen in the hand. It is about using computers to think, as an extension of the brain (Watanabe 2002: 7).

\section{Artificial Intelligence: A Game Played in the Field of the Architects}

In 1950 Alan Turing wrote a very prophetical and provocative paper on Artificial Intelligence, entitled "Computing Machinery and Intelligence" (Turing 1950). ${ }^{1}$ Turing was convinced that if a computer could do all mathematical operations, it could also do everything a person is capable of, a still highly controversial opinion. There are theoretical objections many like to believe that Man, in some subtle way, is superior to the rest of creation and mathematical objections. According to a large number of scientists, computer science will be able to create a machine capable of simulating a fraction of the human minds capacity, at the most.

The English mathematician Roger Penrose is sure that he can demonstrate mathematically that software cannot in any case produce a copy of human intelligence (Penrose 1990). He is convinced that human mind does not work like a computer even those based on neural network analogy following common physical laws, because the rules of intelligence and the mechanism generating thoughts are written in a quantum theory still to be acknowledged.

However, 50 years ago, skipping all the preliminaries, Turing started his paper directly with the question: "Can machines think?" and then went on in less than 30 pages to describe all the hopes and the fears about the possibility of attributing to the machines some specific "human" quality.

He called his method, played in the form of a dialog, the "imitation game." The test that enables us to distinguish a man from a machine is commonly known as Turing test. The Turing test says: "If a computer is found to give answers to questions that cannot be distinguished from answers given by a person, it must be concluded that the computer can think."

Q: Please write me a sonnet on the subject of the Forth Bridge.

A: Count me out on this one. I never could write poetry.

Q: Add 34,957 to 70,764.

A: (Pause about $30 \mathrm{~s}$ and then give as answer) 105,621.

\footnotetext{
${ }^{1}$ Alan Mathison Turing (London 1912-Manchester 1954), Ph.D. mathematics at Princeton in 1938, was a pioneer in computational theory. With David Champernown he wrote the first chess-playing program for computers. He is probably the first to imagine the possibility of machines really thinking. The term "Turing machine" was introduced by Alonzo Church in his review on Turing's paper "On computable numbers" (Church 1937).
} 
Q: Do you play chess?

A: Yes.

Q: I have $\mathrm{K}$ at my K1, and no other pieces. You have only $\mathrm{K}$ at $\mathrm{K} 6$ and $\mathrm{R}$ at R1. It is your move. What do you play?

A: (After a pause of $15 \mathrm{~s}$ ) R-R8 mate.

The question and answer method seems to be suitable for introducing almost any one of the fields of human endeavor that we wish to include (Turing 1950: 434).

Now, let us examine this well-known part of "Computing Machinery and Intelligence" as an exploration of the relationship between Architecture and Artificial Intelligence.

Douglas R. Hofstadter (1979) points out that few people realize that the solution of the arithmetical problem took too long and, above all, the sum is wrong! The fact would be natural if a human being was answering; it would be just a mistake. However, it being a machine, we can think about several possibilities:

- a hardware random error (one that never occurs again);

- a accidental hardware or coding error, which repeated arithmetical mistakes;

- an intentional fault generated by a program code to make the machine wrong in order to introduce incidental arithmetical mistakes and thus deceive the questioner;

- an unexpected phenomenon: the computer program finds it difficult "to think" in the abstract and simply made a "genuine mistake", which it will probably never repeat;

- a joke: the machine has intentionally teased the questioner. . . because is playing the imitation game.

However we can tell that the answerer is a machine because of its incapacity to work out "aesthetic thoughts". People willingly accept a machine able to understand and translate texts, to manipulate symbols (playing chess), to solve algorithms of course, even to have sense of humor. If we admit it is able to joke, it must be unable to shine in beauty competitions.

In fact the idea that Artificial Intelligence is unable to compose poetry supports the argument of the impossibility of producing thinking hardware.

In the beginning of the information science revolution, architects, fascinated by new technologies as well as by biological models, had begun to think along the lines of virtual architecture and the architecture of artificial life. Virtual architecture is more concerned with non-Euclidean geometries and includes architects-video-artists, the trend being to design liquid spaces made with digital materials, moving and transforming images that existing only in the personal computer. The architecture of artificial life follows the new organic paradigm, which is born from the union of auto-generative software and bio-morphic architecture. 

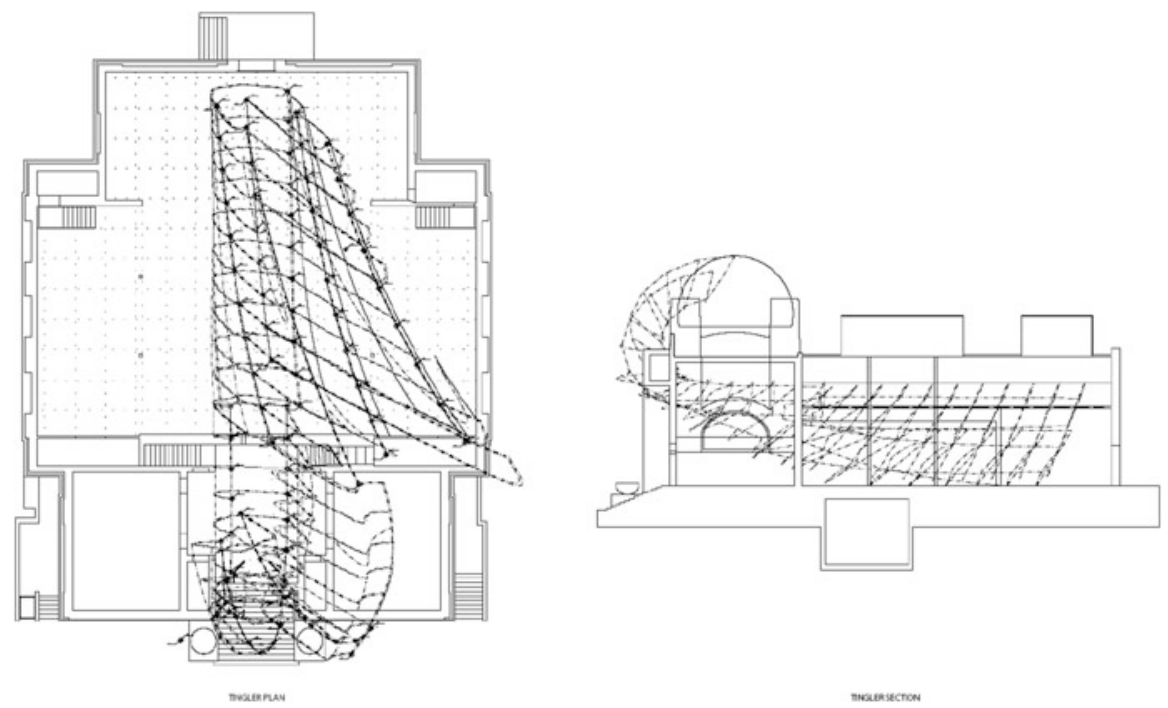

Fig. 86.1 Greg Lynn, The Tingler at the secession house, Vienna, 1999: Plan and section. Image: Courtesy of Greg Lynn FORM

"The Tingler," a painting/architecture hybrid performed in Vienna in the summer 1999, is an example of the architecture of artificial life. Greg Lynn, ${ }^{2}$ together with the Argentine painter Fabian Marcaccio, who now lives in New York, transformed the interiors of Olbrich's Secession House into a disquieting vertebrate, using Alias/Wavefront, Maya and Microstation (Figs. 86.1, $86.2,86.3,86.4$, and 86.5).

The architectural structure from which Marcaccio's paintings were suspended grew out of the golden dome into the Secession House just like the parasite protagonist of William Castle's movie "The Tingler," which was the inspiration for the exhibit. In the film, the bothersome organism was living inside the human backbone and grew bigger as one's fears grew. Analogously in the exhibit, the parasite designed by Lynn/Marcaccio penetrated inside the building, transforming it into an animate form that seemed to have grown so enormous that the walls could hardly contain it (Brizzi 1999).

In other projects by Lynn, animation software and computer-assisted manufacturing are combined to build previously unimaginable, "living" architectural forms. The ideas of the designer are supported by the amazing performances of the machine.

\footnotetext{
${ }^{2}$ Greg Lynn heads up the architecture firm FORM based in Venice, California, where he uses computers to design his wavy structures. His works, according to an article by Mark Dery in Artbyte, "are made possible by the computer's ability to generate warped or fluid forms. A typical Lynn creation is a monstrous hybrid of architectural theory and cyberpunk science fiction" (Dery 2000) Lynn teaches at UCLA and at the University of Applied Arts Vienna.
} 


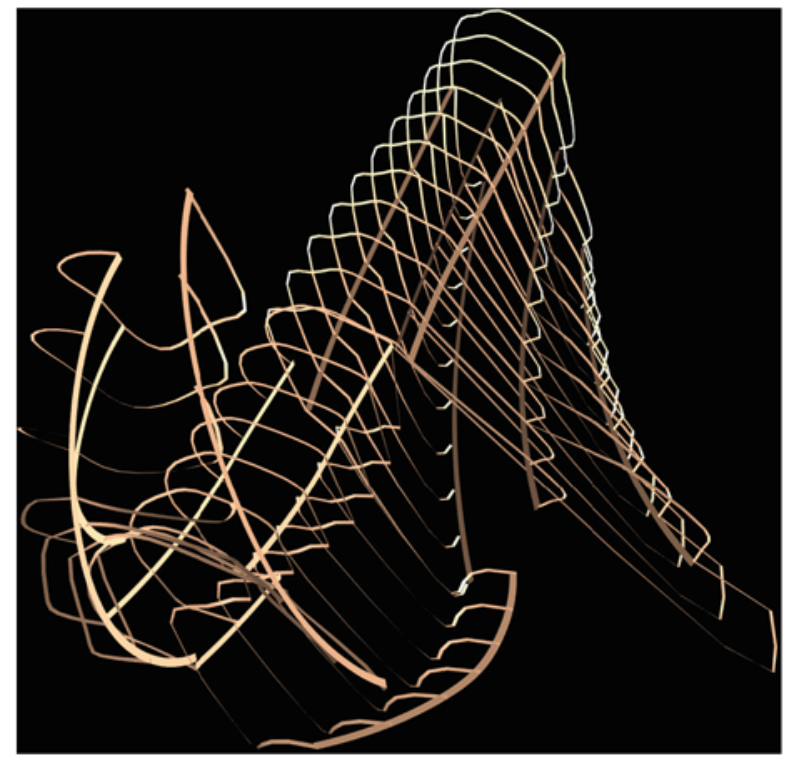

Fig. 86.2 The Tingler. Digital sketch. Image: Courtesy of Greg Lynn FORM

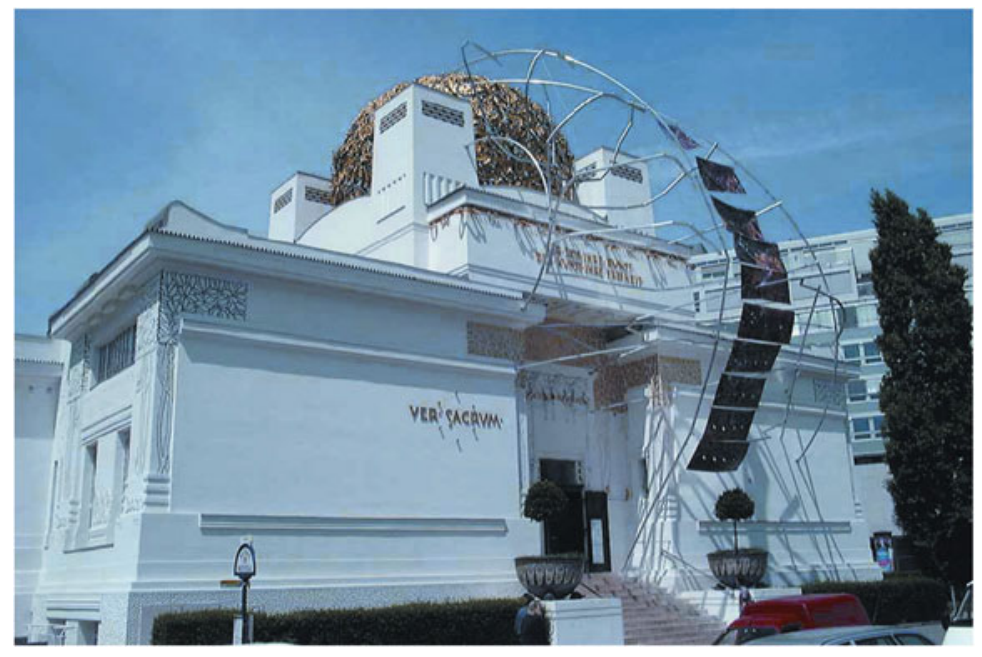

Fig. 86.3 The Tingler, exterior view. Image: Courtesy of Greg Lynn FORM

About 30 years ago, studies concerning pattern language analyzed thinking processes in order to derive a coded method for automated design. The greatest shortcoming of this system was probably only that it was conceived before the age of personal computers, essential instruments for verifying the design processes and acquiring the issues for possible new applications. 


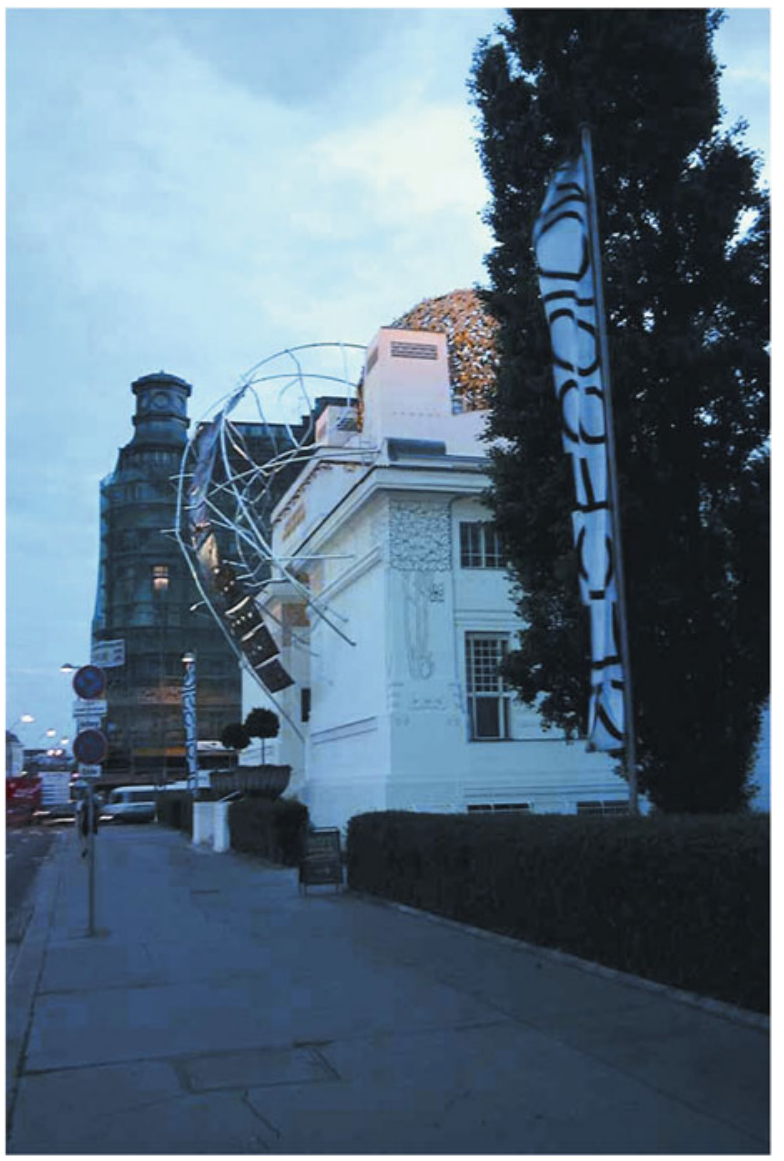

Fig. 86.4 The Tingler, exterior view. Image: Courtesy of Greg Lynn FORM

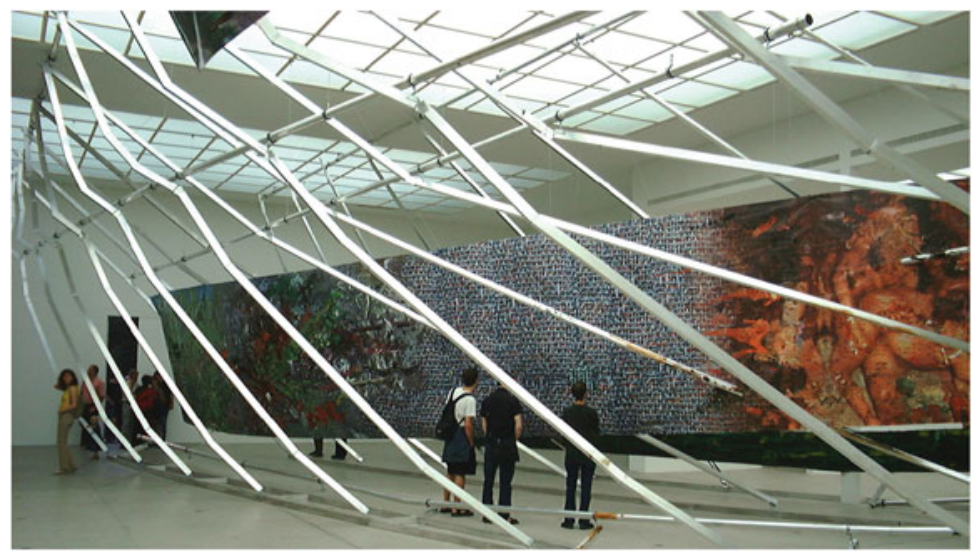

Fig. 86.5 The Tingler, interior view. Image: Courtesy of Greg Lynn FORM 


\section{On Growth of Form}

It is evident that we are introducing a sort of mechanized creativity, as if artificial minds could master an automatic artistic power in order to develop complex systems design.

The Induction Cities ${ }^{3}$ project by architect Makoto Sei Watanabe began in 1994 as research into Program Aided Design, which is capable of proposing solutions to complex building settlements through the use of self-generated computerized programs.

Its procedures are akin to the studies on pattern language. Both are based on the discovery of hidden structures in urban and social systems. Complexity science has discovered simple principles hidden within what appears to be utter disorder. Consequently, instead of imitating forms, it is the process that contributes to design.

The purpose is not to build a grid-pattern city or a labyrinthine town on a whim. It is to present the potentiality of a methodology for creating a city that will be as natural as a spontaneously generated living organism, and will even satisfy certain conditions. From 1994 to 1997 Watanabe made tests of the program, developing a series of different "inducted cities": the Self- and Other-Determining City, the Sun-God City, the On Demand City, the City of Distorted Space, the Comparative District City and the City of Correlative Wave Motion.

Each project uses the computer, combined selected output results, and computer simulation to depict patterns of influence amongst local services, etc., in order to find a fluid order of housing design, accessibility and pleasure.

Unlike conventional design, Induction City is a method for inducing results that meet selected conditions. In planning residential quarters for multi-unit housing architecture in Japan, for instance, access to maximum sunshine for each unit is given top priority. The result of analytical methods, which often tries to decide everything, is sometime monotonous box-like housing complexes. Sun-God City is a program that performs this task automatically: the software combines units randomly and sends sunlight to each. The process is repeated until all the units are optimally arranged. This method can also be applied to create automatic programs for other important conditions such as privacy and access.

On Demand City to take another example is a program created to optimize the location of urban facilities and their relationships.

Because a city is a constantly moving and growing much like a living organism it can be planned by an Evolutionary Design Program, a step forward as regards the programs for City Generative. Again, it is a matter of programs exploiting the power of computers to perform a huge number of procedures quickly and efficiently in order to memorize them, to compare and to evaluate all the potential results. This is just how "Deep Blue," the machine able to play chess and win against the world champion Garry Kasparof, works.

Going beyond the principle of randomness, Makoto Sei Watanabe designed the Iidabashi Subway Station, developing, with his team, the Web Frame project, ${ }^{4}$

\footnotetext{
${ }^{3}$ See the website http://www.makoto-architect.com/idc2000/.

${ }^{4}$ See http://www.makoto-architect.com/idc2000/syb_e2.htm.
} 
Fig. 86.6 Makoto Sei Watanabe. Iidabashi subway station, entrance at street level. The steel is realized straight from the same data files and can be considered the next higher level of generation. Photo: Courtesy Andrew I-kang Li

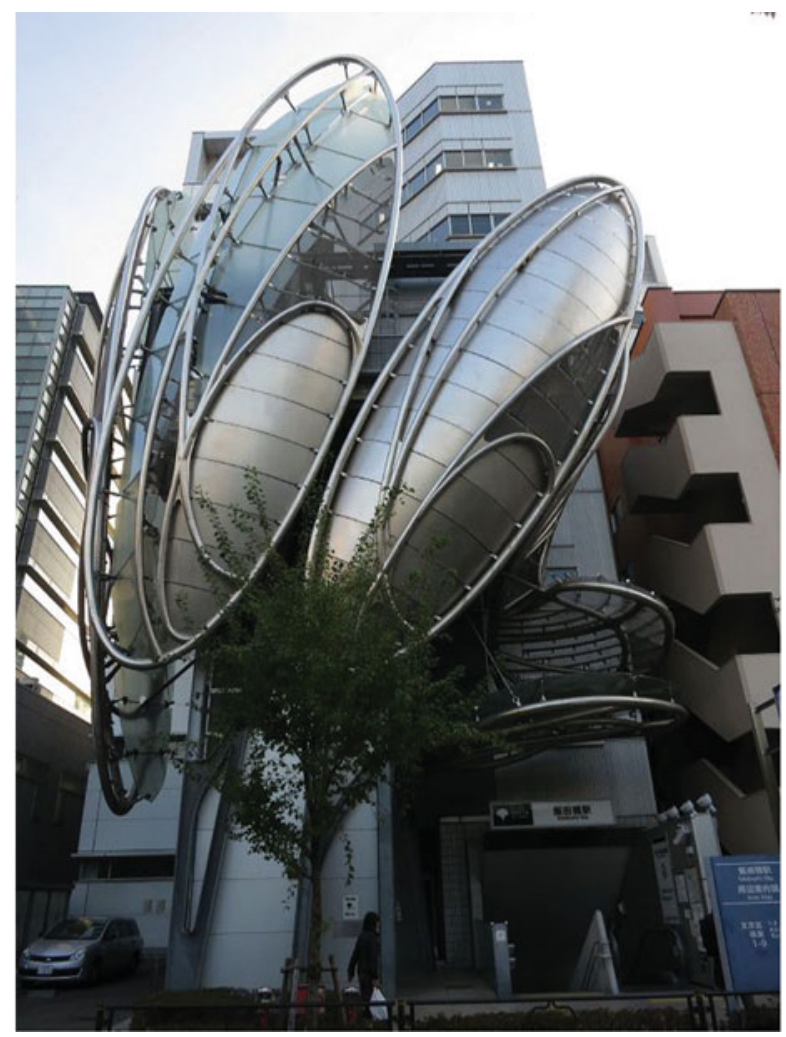

whose aim is to move forward from the first phase of Induction Cities into the field of "aesthetic" evaluation. ${ }^{5}$ Watanabe has explained that they intend the program to satisfy "fuzzy" criteria such as "enjoyable" or "dynamic:"

At this point, we have to return to our earlier question, what is a "good" thing? In City of the Sun Goddess, we chose as an index for evaluation exposure to sunlight, and in On Demand City, our index was distance. ... In both cases, that is, some aspect of "naturalness" showed up. Naturalness is something that everyone can understand. ${ }^{6}$

He continues the same web page, "Why not introduce some principles of nature for example, the laws of motion governing the movements of waves that give such a sense of pleasure?"

The Iidabashi Subway Station is on the Ōedo line of the Tokyo underground (Fig. 86.6). It is the first architecture to be completely carried out by a computer. Completed in October 2000, Watanabe designed it in 1991 after winning a

\footnotetext{
${ }^{5}$ See http://www.makoto-architect.com/WF_II/WF_II_e1.html.

${ }^{6}$ Quoted from http://www.makoto-architect.com/subway/subway_2e.html.
} 


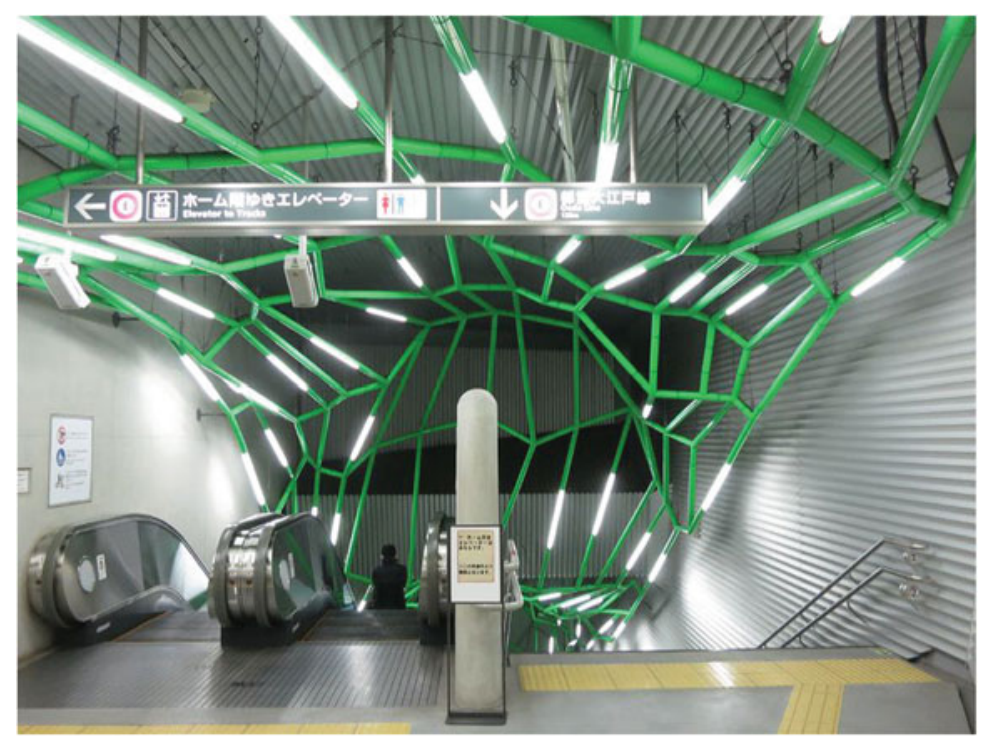

Fig. 86.7 Makoto Sei Watanabe. Iidabashi Subway Station. The electrical equipment network. Photo: courtesy Andrew I-kang Li

competition held by the Tokyo Metropolitan Subway Construction Corporation. He applied the so-called "Induction Subway Project" system associating the city planning with the "Induction cities".

The principles on which the subway station are based are the same as in two other architectural designs by Watanabe, the "K-Museum," rising in the very heart of an incipient city, and "Fluid Cites Fiber Waves", designed just like a living organism to interact with the visitors of the 2000 Venice Biennale. Both are conceived "to make visible the invisible."

Iidabashi's subway passages and flow patterns constitute a submerged space that delineates physical and virtual routes which are no more complex, however, than the intense maze of the city's nameless streets above ground. Both the city and the underground accommodate the daily transit of people (whose level of stress and feeling of disorientation is even greater underground), electrical systems, lighting circuits, rainwater conducts (Figs. 86.7 and 86.8).

The design is anticipated by Tokyo's urban configuration: roads which appear to follow a regular right angled grid pattern imperceptibly deviate from the orthogonal; the disorientation is accentuated by urban blocks not having a building number sequence, thus only by knowing the neighbourhood it is possible to reach any address. Consequently, the aid of clear, outstanding informative signs indicating physical reference landmarks becomes indispensable so as to find one's way amidst the city's urban layout, both above the ground and below.

Watanabe followed his guideline theory by inserting multi-sensory signalling icons in the underground area. Large installations and small figurative works run across its multimedia routes so that "to see is to touch." 
Fig. 86.8 Makoto Sei Watanabe. Iidabashi Subway Station. The electrical equipment network. Photo: courtesy Andrew I-kang Li

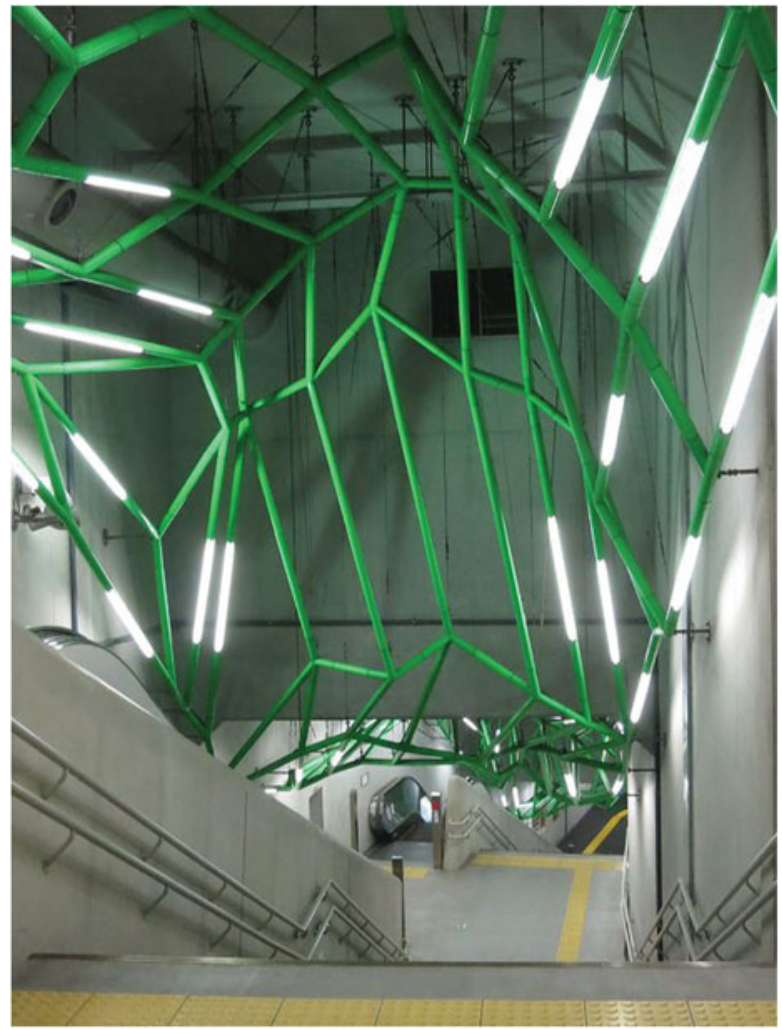

Hence Watanabe's architectural design comes very close to the objective of being a total communication media governing the theoretical as well the actual physical space, constantly mediating between the mind's logical processes with its sensory systems.

The exposed networks of old and new tube routes that were visible during the excavation to construct this underground extension were especially suggestive. The 13 subway lines that wind their ways beneath the surface of Tokyo delineate a topological system resembling fossils suspended "in mid-air" (or should we say "in mid-ground"?). Visible only for a short time before being buried below the earth once more, the construction project truly made the invisible visible, in terms of urban structure, its beauty, and indeed its character.

Trans-sensorial clues reveal directions and destinations from the inside as well. A portion of a wall is treated with a Braille-like texture to enhance the juxtaposition of visual and tactile feelings (Fig. 86.9).

If one "reads" with one's fingertips of the fingers the phrase embossed on a metallic surface, "WOODEN SURFACE TREATMENT," two sensations became superimposed, a tactile feeling and a visual image. The knowledge we have of the different sensory experiences translates in our mind as messages that begin a 


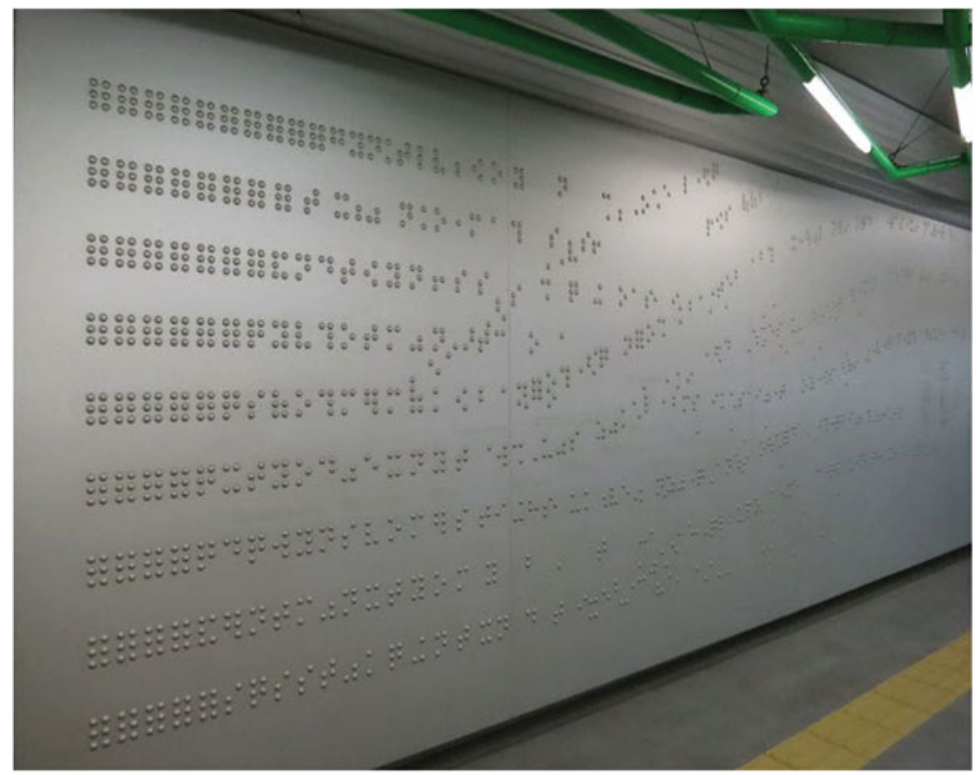

Fig. 86.9 Makoto Sei Watanabe. Iidabashi subway station. Braille wall. Photo: Courtesy Andrew I-kang Li

process of transferring information from a state of self-consciousness to one of subconscious feelings and vice versa: a sort of perceptual oxymoron.

The whirl of the staircase handrails and of connecting routes between Iidabashi station and the other underground levels make evident, like a collection of superimposed layers, the topological structure of the site.

The network of underground conduits in this part of the Tokyo subway is organised through three adjacent parallel tunnels, the central one being the station proper, the lateral ones where the rail lines run.

In coherence with the initial premise making visible the invisible the central tunnel's ceiling was substituted by juxtaposed technological conduits lying in a cavity aligned longitudinally with the pedestrian walkway. Finally, from the depths, $35 \mathrm{~m}$ below the city, a steel flower blooms and germinates: this is "Wing," the ventilation tower housing all the technological equipment for the entire subway station (Fig. 86.10).

The mechanism of auto-generation seeks more water, more light, just like "Elsie" (Electro Light Sensitive Internal External) and "Elmer" (Electro Mechanical Robot) built in 1948 by Walter Gray Walter, an English neurophysiologist who amused himself by fabricating cybernetic beings. ${ }^{7}$

\footnotetext{
${ }^{7}$ The intriguing history of Artificial Intelligence, from the first self-acting machines up to modern artificial life, is told by Castelfranchi and Stock (2000).
} 
Fig. 86.10 Makoto Sei Watanabe. Iidabashi subway station: the Wing. Photo: Courtesy Andrew I-kang $\mathrm{Li}$

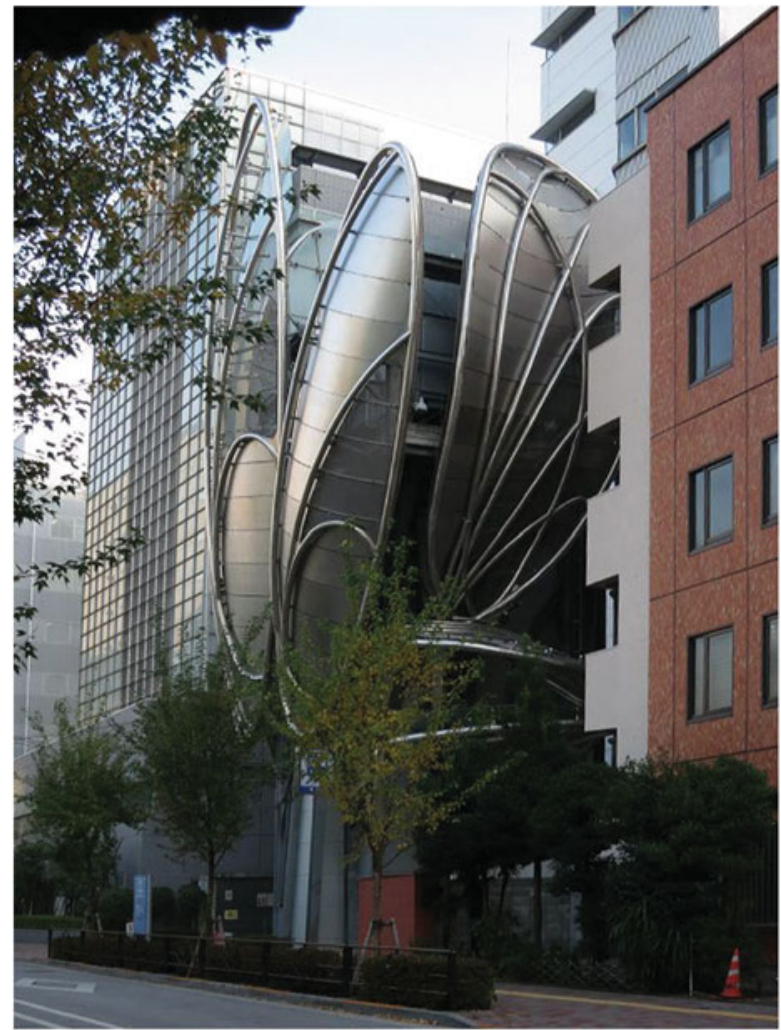

\section{Conclusions}

All digital computers now operate according to sequences of rules that the machine follows step by step. A methodical exploration of computing theory brought Penrose to criticize one of its philosophical corner-stones, the Turing test. However, many computer scientists accept the test as a valid way of distinguishing an intelligent program from a non-intelligent one, and a machine from a human being.

After all, whether the program happens to be executed by a man or by a computer makes no difference. It is not even a matter of believing whether it is possible or not to achieve Artificial Intelligence, because some of the consequences of the first attempts of computer science to create a huge thinking machine are already useful design instruments.

In conclusion, in order for software developed for architecture to pass the Turing Test, it must not only pretend to be human but also show an amazing capacity for optimizing design choices and generating architectural organisms comparable with those produced by humans, as well as and above all demonstrate its capacity to generate aesthetically definable figures. (Our purpose here is not to argue the beauty 
of digital architecture!) To the first question of the test, "Please write me a sonnet on the subject of the Forth Bridge," or if we like, "Please draw me a folded building or an optimized new town," the machine will not answer, "Count me out on this one. I never could write poetry or draw architecture," but rather, "Yes, you can choose amongst the following solutions...", thus winning the imitation game.

Acknowledgment I wish to thank Andrew I-kang Li for taking the wonderful photographs of the Iidabashi Subway Station.

Biography Alessandra Capanna is an Italian architect living and working in Rome. She received a degree and a PhD in Architecture from University of Rome "La Sapienza". Among her published articles on mathematical principles both in music and in architecture are: "Una struttura matematica della composizione", remarking the idea of self-similarity in composition; "Music and Architecture. A cross between inspiration and method", about three architectures by Steven Holl, Peter Cook and Daniel Libeskind (Nexus Network Journal 11, 2 (2009); "Iannis Xenakis. Combinazioni compositive senza limiti", "Limited, Unlimited, Uncompleted. Towards The Space Of 4d-Architecture" and "Tesseract Houses", about the topic of conceiving higher dimension architectures. She is a Ricercatore at the Faculty of Architecture of Rome "La Sapienza". She is the author of Le Corbusier. Padiglione Philips, Bruxelles (Universale di Architettura 67, 2000), on the correspondence between the geometry of hyperbolic paraboloids and technical and acoustic needs, and its aesthetics consequences.

\section{References}

BRIzzI. M. 1999. Greg Lynn. Diagrammi d'una esposizione. Arch' it - IN A BIT, http://architettura. it/inabit/19990930/.

Castelfranchi, Y. \& Stock, O. 2000. Macchine come noi. La scommessa dell'Intelligenza Artificiale. Rome-Bari: Ed. Laterza.

Снurch, Alonzo. 1937. Review: A. M. Turing, On Computable Numbers, with an Application to the Entscheidungsproblem. Journal of Symbolic Logic 2, 1: 42-43.

DerY, Mark. 2000. Soft House: Home Grown. Artbyte, November-December 2000. http://www. artbyte.com/mag/nov_dec_00/lynn_content.shtml.

Hofstadter, D. R. 1979. Gödel, Escher, Bach: an Eternal Golden Braid. New York: Basic Books Inc.

Penrose, R. 1990. The Emperors New Mind. Oxford: Oxford University Press.

TuRING, A. M. 1950. Computing Machinery and Intelligence. Mind 59: 433-460.

Watanabe, Makoto Sei. 2002. Induction Design: A Method for Evolutionary Design. Basel: Birkhäuser. 


\section{Contents for Volume II}

48 The Revolutionary, The Reactionary and The Revivalist:

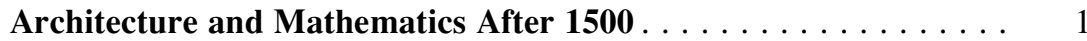

Michael J. Ostwald and Kim Williams

Part VII Theories of Representation

49 Architecture, Mathematics and Theology in Raphael's Paintings . . . . 31 David Speiser

50 Raphael and the Pantheon's Interior: A Pivotal Moment in Architectural Representation . . . . . . . . . . . . . . . 43 Kristina Luce

51 Design and Perspective Construction: Why Is the Chalice the

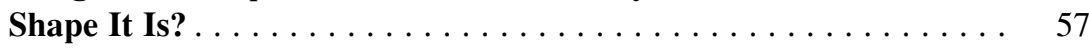
Richard Talbot

52 Perspective in António Rodrigues's Tratado de Arquitectura . . . . . . 73 João Pedro Xavier

Part VIII 1500 A.D.-1900 A.D.

53 Ottoman Architecture: Relationships between Architectural Design and Mathematics in Sinan's Works . . . . . . . . . . . 95 Zafer Sağdiç

54 The Mathematics of Palladio's Villas . . . . . . . . . . . . . . . . 107 Stephen R. Wassell

55 Golden Proportions in a Great House: Palladio's Villa Emo . . . . . 121 Rachel Fletcher

56 The Hidden Pavement Designs of the Laurentian Library . . . . . . . 139 Ben Nicholson, Jay Kappraff, and Saori Hisano 
57 Measuring up to Michelangelo: A Methodology . . . . . . . . . . . . 151 Paul A. Calter and Kim Williams

58 António Rodrigues, a Portuguese Architect with a Scientific

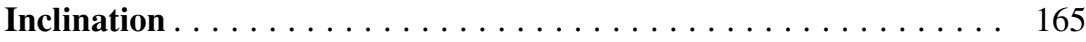
João Pedro Xavier

59 Villalpando's Sacred Architecture in the Light of Isaac Newton's

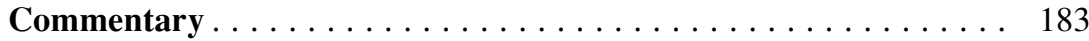

Tessa Morrison

60 Coelum Britannicum: Inigo Jones and Symbolic Geometry . Rumiko Handa

61 The Science Behind Francesco Borromini's Divine Geometry . . . . . 217 John G. Hatch

62 Transformational Geometry and the Central European Baroque Church ........................ 231 John Clagett

63 Are There Connections Between the Mathematical Thought and Architecture of Sir Christopher Wren? . . . . . . . . . . . . . . 243 Maria Zack

64 Robert Hooke's Fire Monument: Architecture as a Scientific Instrument . . . . . . . . . . . . . . . . . . . . . . 257 Maria Zack

65 Practical and Theoretical Applications of Geometry at Claude Perrault's Observatoire de Paris (1667-1672) . . . . . . . . 269 Randy S. Swanson

\section{Part IX 1800-2000}

66 Geomantic (Re)Creation: Magic Squares and Claude Bragdon's Theosophic Architecture . . . . . . . . . . . . . . . . . . . . . 289 Eugenia Victoria Ellis

67 Mathematics and Music in the Art Glass Windows of Frank Lloyd Wright . . . . . . . . . . . . . . . . . . . . . . . . 305 Leonard K. Eaton

68 Fractal Geometry in the Late Work of Frank Lloyd Wright: The Palmer House . . . . . . . . . . . . . . . . . . . . . . . . . . . 325 Leonard K. Eaton

69 Characteristic Visual Complexity: Fractal Dimensions in the Architecture of Frank Lloyd Wright and Le Corbusier . . . . . . . . 339 Michael J. Ostwald, Josephine Vaughan, and Chris Tucker 
70 From Cosmic City to Esoteric Cinema: Pythagorean Mathematics

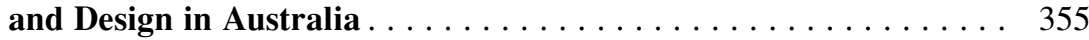

Graham Pont and Peter Proudfoot

71 The Ruled Geometries of Marcel Breuer . . . . . . . . . . . . . . . . 367 John Poros

72 Conoids and Hyperbolic Paraboloids in Le Corbusier's Philips

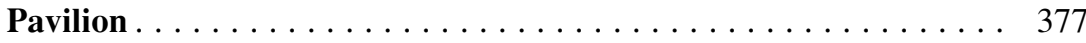
Alessandra Capanna

73 Oscar Niemeyer Curved Lines: Few Words Many Sentences . . . . . 389 Benamy Turkienicz and Rosirene Mayer

74 Dom Hans van der Laan and the Plastic Number . . . . . . . . . . . . 407 Richard Padovan

75 Louis Kahn's Platonic Approach to Number and Geometry . . . . . . 421 Steven Fleming

76 The Salk: A Geometrical Analysis Supported by Historical Evidence . . . . . . . . . . . . . . . . . . . . . . . . . . 435 Steven Fleming and Mark A. Reynolds

Part X Contemporary Approaches to Design and Analysis

77 Architecture and Mathematics: Soap Bubbles and Soap Films . . . . . 449 Michele Emmer

78 Aperiodic Tiling, Penrose Tiling and the Generation of Architectural Forms . . . . . . . . . . . . . . . . . . . . . . . 459 Michael J. Ostwald

79 Paving the Alexanderplatz Efficiently with a Quasi-Periodic Tiling Ulrich Kortenkamp

80 Generation of Architectural Forms Through Linear Algebra . . . . . 483 Franca Caliò and Elena Marchetti

81 The Praxis of Roman Geometrical Ordering in the Design of a New American Prairie House . . . . . . . . . . . . . . . . . . . 497 Donald J. Watts

82 Exploring Architectural Form in Perspective: A Fractal Hypercube-Building

Tomás García-Salgado

83 The Compass, the Ruler and the Computer: An Analysis of the Design of the Amphitheatre of Pompeii . . . . . . . . . . . . . . 525 Sylvie Duvernoy and Paul L. Rosin 
84 Correlation of Laser-Scan Surveys of Irish Classical Architecture with Historic Documentation from Architectural Pattern Books . . . . 541 Maurice Murphy, Sara Pavia, and Eugene McGovern

Part XI Theories and Applications of Computer Sciences

85 Mathematics and Architecture Since 1960 . . . . . . . . . . 553 Lionel March

86 BiOrganic Design: A New Method for Architecture and the City . . . . 579 Alessandra Capanna

87 Formal Mutations: Variation, Constraint, Selection . . . . . . . . . 593 Andrzej Zarzycki

88 The Role of Mathematics in the Design Process Under the Influence of Computational and Information Technologies . . . . . 609 Arzu Gönenç Sorguç

89 Generative Design Grammars: An Intelligent Approach Towards Dynamic and Autonomous Design . . . . . . . . . . . . . . 619 Ning Gu

90 Ethics and Geometry: Computational Transformations and the Curved Surface in Architecture . . . . . . . . . . . . . . . 633 Michael J. Ostwald

91 Equiangular Numbers . . . . . . . . . . . . . . . . . . . . . . . . . . . . . . 649 Henry Crapo and Claude Le Conte De Poly-Barbut

92 Architecture as Verb and the Ethics of Making . . . . . . . . . . . . 661 Alberto Pérez-Gómez

Index for Volume II . . . . . . . . . . . . . . . . . . . . . . . . . . . . . . 675

Index for Volume $\mathbf{I} \ldots \ldots \ldots \ldots \ldots$. . . . . . . . . . . . . . . . 683 


\section{黛 Springer}

http://www.springer.com/978-3-319-00142-5

Architecture and Mathematics from Antiquity to the Future Volume II: The 1500 s to the Future Williams, K.; Ostwald, M.J. (Eds.)

2015, XIX, 690 p. 365 illus., 79 illus. in color., Hardcover ISBN: $978-3-319-00142-5$

A product of Birkhäuser Basel 